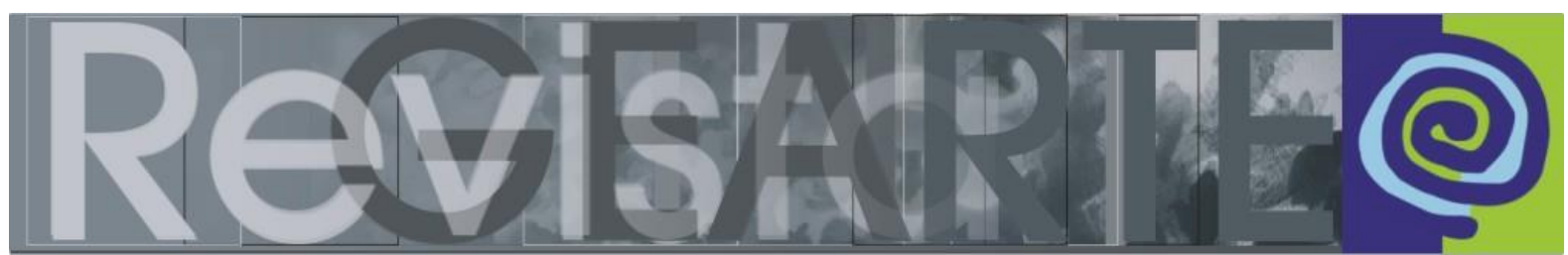

ISSN 2357-9854 | e-ISSN 2596-3198 (online)

\title{
Desenho infantil e o Ensino de Artes Visuais: desenhando com crianças com deficiência intelectual
}

\author{
Liane Carvalho Oleques \\ (Universidade do Estado de Santa Catarina - UDESC, Florianópolis/SC, Brasil)
}

\begin{abstract}
RESUMO - Desenho infantil e o Ensino de Artes Visuais: desenhando com crianças com deficiência intelectual - Qual a importância de saber sobre o desenvolvimento e as características do desenho na infância? Como esse desenho se desenrola diante de especificidades, como a deficiência intelectual? E como ensinar crianças com deficiência a desenhar? Este trabalho aborda questões acerca do desenho infantil, seu desenvolvimento e características, além de contar com estratégias de ensino de desenho para crianças com deficiência intelectual. Pesquisadores do desenho infantil, como Luquet (1969) e Duarte (2011), fornecem a base teórica, nesse trabalho, necessária à compreensão dessas questões. É apresentado um pequeno recorte da coleta de dados da pesquisa de doutorado, mostrando a experiência de ensino e aprendizagem de desenho com Beta, menina de 13 anos, usuária da APAE (Associação de Pais e Amigos dos Excepcionais) de uma cidade do Sul do Brasil, onde foram realizadas as atividades de desenho.
\end{abstract}

PALAVRAS-CHAVE

Desenho Infantil. Ensino das Artes Visuais. Deficiência Intelectual.

ABSTRACT - Children's drawing and Visual Art Education: drawing of children with intellectual disabilities - How important is the knowledge about the development and characteristics of drawing in childhood? How drawing unfold in the face of specificities, such as intellectual disability? And how to teach disabled children to draw? This work deals with questions about children's drawings, their development and characteristics, as well as strategies for teaching drawing for children with intellectual disabilities. Researchers of children's drawings such as Luquet (1969) and Duarte (2011) give the theoretical basis necessary in this work to understand these issues. A small clipping of the data collection from doctoral research is presented, showing the teaching and learning experience of drawing with Beta, a 13 years old girl who participates in APAE (Association of Parents and Friends of the Exceptional), in a southern Brazilian city, where the drawing tasks were carried out.

\section{KEYWORDS}

Children's Drawing. Visual Art Education. Intellectual Disability.

O presente artigo traz um recorte da minha pesquisa de doutorado intitulada "Uma possibilidade de ensino de desenho para crianças com deficiência intelectual" (2017). O trabalho visou a criação de estratégias de ensino de desenho para crianças com deficiência intelectual, a aplicação e análise do processo de aprendizagem. Portanto, este texto aborda considerações sobre a importância do desenho infantil e seu ensino diante dessas especialidades. 


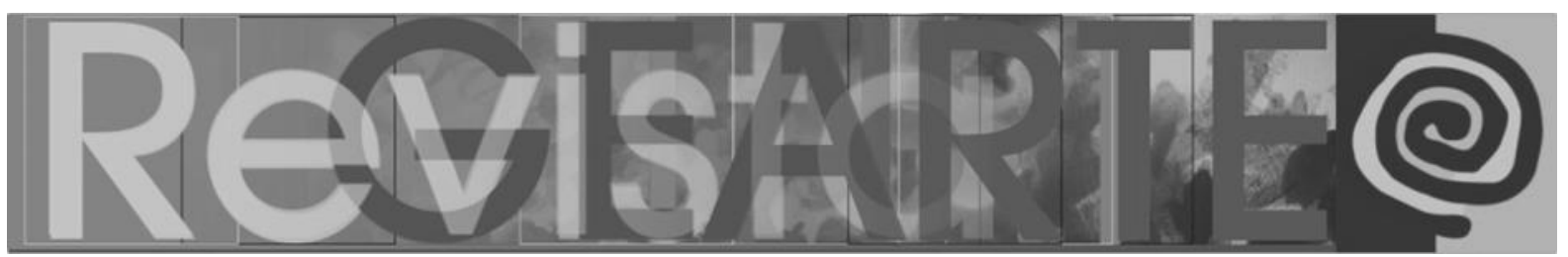

Se você é ou já foi professor em uma escola de educação inclusiva, certamente já se deparou com algum aluno com deficiência, seja sensorial, intelectual ou múltipla. É possível também que você tenha se perguntado como trabalhar com este aluno. Alunos com deficiência demandam estratégias educativas específicas e tanto a escola como o professor devem estar preparados para atender suas particularidades.

Como professora de Artes Visuais também me deparei com esta realidade, principalmente quando comecei a trabalhar na Associação de Pais e Amigos dos Excepcionais - APAE - instituição que atende adultos e crianças com deficiências, onde atendi alunos com deficiência intelectual das mais diferentes idades. Nesse período, pude perceber que alunos adultos, sem comprometimentos motores, encontravam-se nas primeiras etapas do desenho infantil, tais como as garatujas. Inicialmente, relacionei essa realidade ao fato de esses alunos pouco terem exercido ou desenvolvido a prática de desenhar além do comprometimento intelectual. Então, como fazer para que meus alunos ainda crianças não tivessem o mesmo futuro de seus colegas mais velhos? Saber desenhar e interpretar esquemas gráficos usuais poderiam ajudá-los no processo de desenvolvimento motor, cognitivo e na linguagem?

Já compreendendo aspectos do desenho infantil, comecei a criar estratégias de ensino de desenho como, por exemplo, jogos de esquemas gráficos e moldes vazados, que puderam ser aprimorados nos estudos de doutorado. Mas por que ensinar desenho para alunos com deficiência intelectual?

É importante que crianças com deficiência intelectual aprendam a desenhar, pois essa atividade desencadeia processos mentais de memorização e aprendizagem que auxiliam na aquisição de conceitos e da linguagem verbal, bem como a possibilidade de ampliar as relações entre objeto e desenho. Muitos alunos com deficiência intelectual necessitam da Comunicação Alternativa, um recurso de Tecnologia Assistiva destinada à comunicação por meio de símbolos gráficos que expressam mensagens. Além disso, o ensino de desenho para alunos com deficiência 


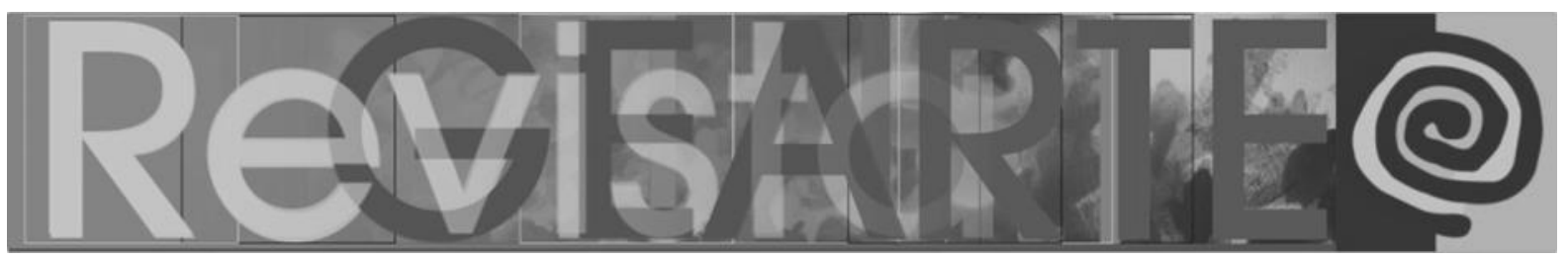

intelectual promove a inclusão nas classes comuns de ensino, permitindo que o aluno com deficiência compartilhe das atividades propostas em sala.

Embora eu fale aqui em Ensino das Artes Visuais, aquilo que proponho não diz respeito ao Ensino da Arte como capacidade expressiva de livre criação gráfica, mas sim de um desenho cuja função é mais comunicacional do que artística. Conforme discorre a professora Dra. Maria Lúcia Duarte, que dedicou suas pesquisas ao desenho infantil e adolescente:

Considero o ato de desenhar na infância um recurso cognitivo, mental, compreendo que ao desenho corresponde uma imagem mental visual, capaz de permitir pensar por meio dela, porque apresenta os objetos do mundo de um modo genérico e simplificado. (DUARTE, 2011, p. 43)

É este desenho, genérico, simplificado e amplamente repetido pelas crianças que abordo neste momento. Noto, porém, o quanto este desenho é menosprezado no ambiente escolar sem que a maioria dos professores compreenda sua importância como um recurso cognitivo e comunicacional.

Aprender a desenhar esquemas gráficos usuais também permite que o aluno, com ou sem deficiência, possa se expressar de forma artística e criadora, uma vez que artistas como Tarsila do Amaral e Mário Rubinski, por exemplo, se apropriavam desses desenhos para construir suas paisagens. Veremos mais adiante que as crianças participantes da pesquisa não sofreram nenhum bloqueio inventivo, pelo contrário, a aprendizagem do esquema gráfico ensinado permitiu a criação de outros pormenores na cena.

\section{Sobre o desenho infantil}

"A criança desenha para se divertir" afirma Luquet (1969, p. 15) que defende o ato de desenhar como uma atividade lúdica no desenvolvimento da criança. Os estudos de Georges-Henri Luquet (1969) produzidos ainda no início do século XX abordam questões sobre os elementos do desenho infantil, como o tipo e o modelo interno e sua evolução do ponto de vista cognitivo - das garatujas até o desinteresse 


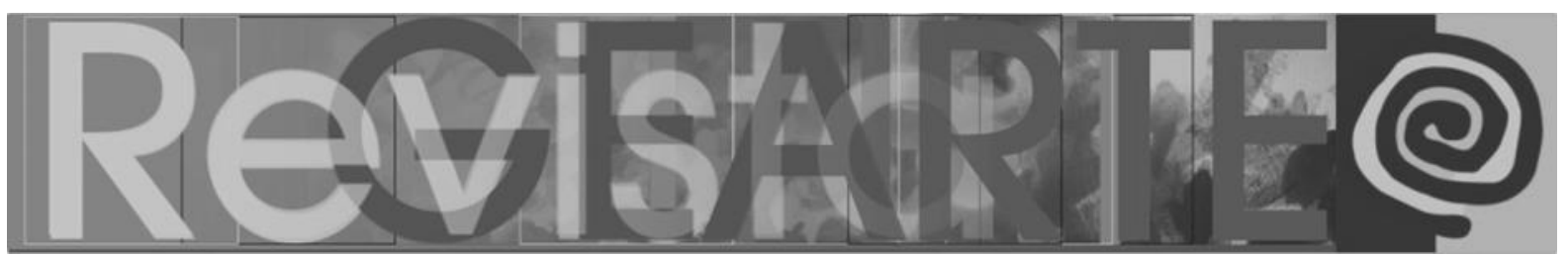

pelo desenho no final da infância e início da pré-adolescência. O autor faz suas considerações por meio de desenhos de crianças de diversas nacionalidades e analisando minuciosamente o processo e desenvolvimento de sua filha.

A partir dessas observações, o autor verificou um tipo de desenho que contemplava formas e traços repetidos, pelas crianças, durante um determinado tempo. O tipo, entendido por Luquet (1969, p. 57) seria: “[...] a representação que uma determinada criança dá a um mesmo objeto ou motivo através da sucessão dos seus desenhos (...)". Em suma, o desenho considerado como tipo é o uso do mesmo modelo gráfico durante um determinado tempo para representar um objeto. Como exemplo, é possível citar as primeiras representações de figura humana das crianças, caracterizadas pelo círculo da cabeça e dois filamentos.

A essa mesma forma de reprodução de um modelo, Luquet (1969) chamou de conservação de tipo. O autor afirma, também, que essa conservação do tipo pode impedir a criança de ver determinadas imperfeições em seus desenhos ou, ainda, opondo-se a aceitar modificações quando estas lhe são indicadas. Segundo Luquet, a conservação de tipo pode caracterizar-se pelo automatismo gráfico: "[...] a reprodução apenas pode explicar-se pela rotina" (LUQUET, 1969, p. 63).

À medida que a criança começa a acrescentar novos detalhes em seus desenhos que não se viam em exemplares anteriores, há uma alteração em seus modos de desenhar, os quais Luquet denominou modificação do tipo. De acordo com esse autor, a modificação do tipo pode apresentar-se não somente por objetos reais, mas por modelos ou desenhos de outras crianças ou adultos.

Todavia, essas conservações que permanecem no desenhar infantil obedecem, conforme Luquet (1969), ao modelo interno, que seria correspondente à realidade psíquica existente na mente da criança. Desse modo, algum tipo de desenho produzido por um indivíduo pode ser repetido inúmeras vezes ou até mesmo por toda sua vida. Assim, o modelo interno obedeceria a uma imagem mental que antecipa o desenhar, seja de uma criança ou de um adulto. 


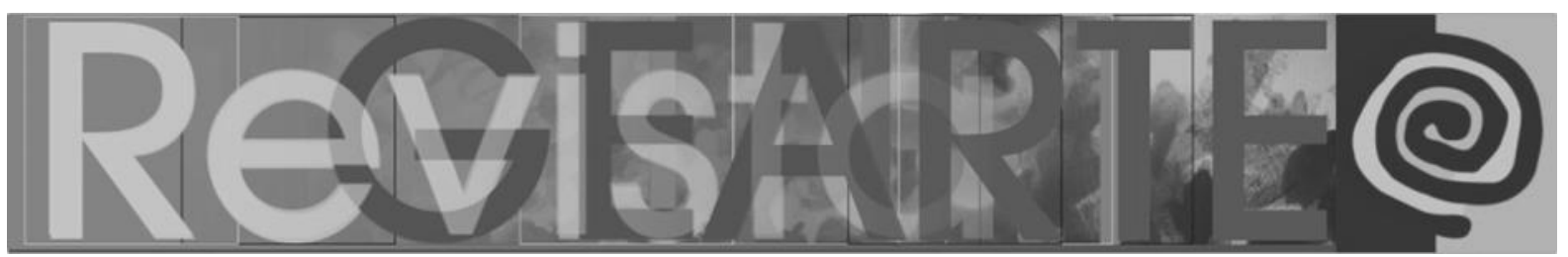

O modelo interno, nesta perspectiva, corresponde aos desenhos realizados de memória, mesmo quando se tem a intenção de copiar um objeto real. Sendo que, este último, apenas serve de sugestão.

[...] mas é ainda esse modelo que a criança cópia mesmo quando se propôs reproduzir um objeto (motivo ou modelo) que tem diante dos olhos. [...] A prova é que os desenhos do natural e os copiados apresentam os mesmos caracteres que os desenhos de memória, cuja característica principal é serem conformes, não ao realismo visual, mas ao realismo intelectual. (LUQUET, 1969, p. 82)

Assim, é possível perceber em desenhos de crianças pequenas a presença de elementos que compõem o objeto real, que não são visíveis, mas que a criança sabe que estavam lá, considerando-os essenciais em seu desenho para que ele faça sentido. Geralmente, esses elementos não visíveis estão atrelados à função do objeto. Como exemplo temos o sino desenhado com o badalo. O modelo interno também se caracteriza por representar um exemplar (genérico) típico de uma categoria de objetos, como o desenho da casa ou da flor.

Duarte (2011) refere-se ao que chamou de esquema gráfico (termo utilizado para definir a produção de desenhos que servem para identificar toda uma categoria de objetos) e, embora Luquet (1969) não tenha adotado esse mesmo termo "esquema" por questões conceituais que impregnavam o termo em sua época, a autora o utiliza em função de o termo transmitir com segurança a ideia de síntese no desenho infantil.

Partindo dessas questões, é possível compreender o desenho infantil dentro do âmbito em que a criança, ao desenhar, estabelece relações de generalização com o objeto a ser representado, ou seja, esses objetos são sintetizados, de forma que a criança representa, apenas em um primeiro momento, suas características mais gerais e significativas. Duarte (2011) dá o exemplo de crianças que, desenhando animais, expressam verbalmente as propriedades formais mais significativas de cada animal, compreendendo-o como um exemplar de uma categoria. Referindo-se ao desenho de coelho realizado por Gabriel, Duarte (2011) observa: "Vários recursos 


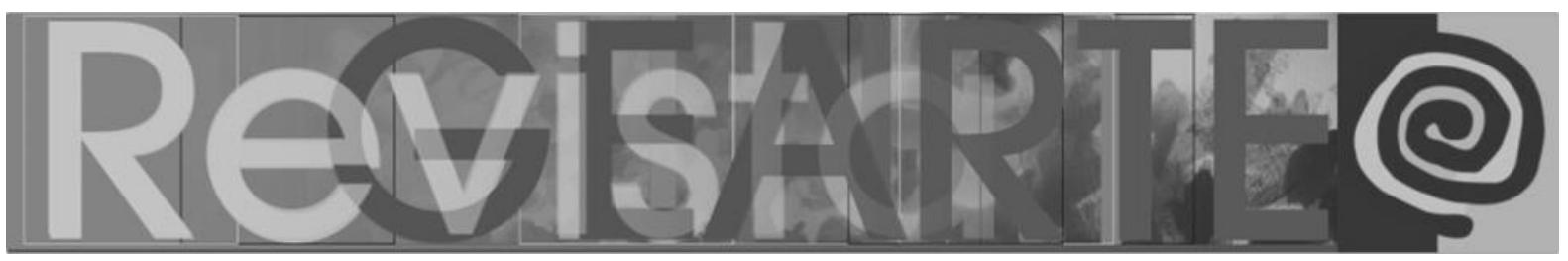

gráficos usados para enfatizar a 'aparência' do animal, e suas propriedades formais, surgem claramente na explicação de Gabriel: orelhas 'pontudas', olhos 'redondinhos', rabo como uma 'bolinha bem fofa'”. (DUARTE, 2011, p. 66)

Nesta concepção, a autora complementa que um esquema gráfico é construído por linhas, em especial as horizontais e verticais, e formas geométricas como círculo, o quadrado e o triângulo.

O desenho infantil concebido como uma síntese representa, evoca os objetos por meio de configurações gráficas construídas a partir de linhas e planos. Os planos, ou espaços oclusivos, tem como referência formas básicas (geométricas) que resumem, no espaço bidimensional, as múltiplas aparências dos objetos do mundo. (DUARTE, 2011, p. 31)

É esse desenho esquemático, construído a partir de linhas e figuras geométricas, que foi usado para a confecção dos esquemas gráficos trabalhados durante minha pesquisa e que relatarei a seguir.

\section{Desenhando os bichos}

"Professora, como se desenha um gatinho?", "Como se faz um coelho?", "Professora, como se desenha uma bicicleta?" Quantas vezes já ouvimos estas perguntas numa aula de artes? Contudo, nem sempre encontramos respostas satisfatórias.

$\mathrm{Na}$ coleta de dados da pesquisa de doutorado trabalhei com duas turmas de AEE$^{1}$ (Atendimento Educacional Especializado) atendidas pela APAE totalizando seis participantes. O recorte da análise dos dados apresentados aqui refere-se a uma das turmas com quatro participantes com idades entre 11 e 14 anos, todos com deficiência intelectual. A coleta de dados nessa turma deu-se no período destinado às aulas de artes, 45 minutos semanais, de março a dezembro. Nesse período foram trabalhadas propostas de desenho livre e direcionadas. As propostas direcionadas consistiram em

1 Na época da pesquisa o termo para este tipo de atendimento era SAEDE (Serviço de Atendimento Educacional Especializado). 


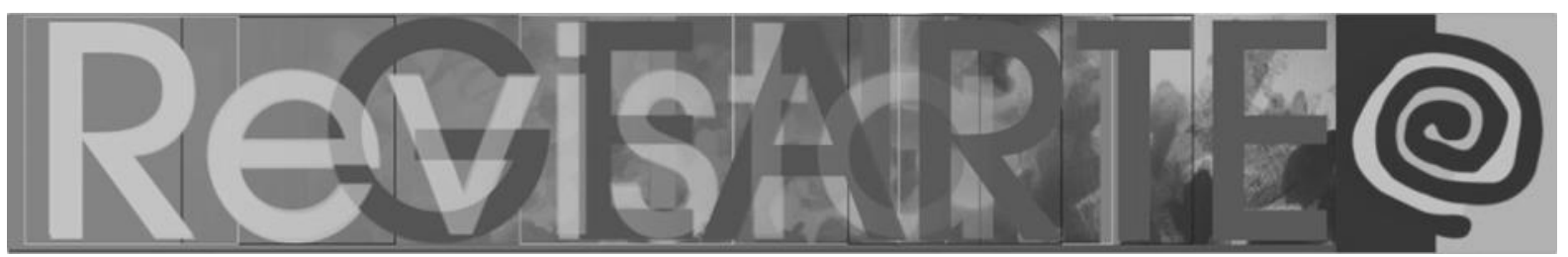

estudos de linhas, figuras geométricas, seleção junto às crianças dos esquemas gráficos que seriam trabalhados, jogos de montar das figuras selecionadas e, por fim, o desenho dos esquemas gráficos.

Para a escolha dos esquemas de bichos, levei aos participantes uma série de figuras de bichos retiradas do livro Vocabulário Pictográfico (DUARTE; PIEKAS, 2013), no qual todos os esquemas são basicamente compostos de linhas retas e curvas, ponto e figuras geométricas. Com exceção da figura do cavalo, que não estava no livro e foi construída a partir dos mesmos princípios dos esquemas do livro. Ao todo, nessa turma, foram trabalhados quatro tipos diferentes de animais.

Os esquemas eram trabalhados por etapas. Inicialmente conversávamos sobre as características de cada animal: onde eles habitavam, o som de cada animal, o número de patas, a cauda, as orelhas, o focinho, os bigodes e, em alguns casos, até mesmo imitávamos o caminhar de cada animal. Em seguida, os participantes desenhavam seus bichos sem a referência do esquema gráfico, e após era apresentado o jogo do esquema (peças de cartolina de cada parte do animal como cabeça, barriga, patas, cauda, orelhas, etc.). Depois que cada participante montava o jogo, eles começavam o desenho a partir do esquema dado. Ou seja, as tarefas seguiram a seguinte sequência: 1 . desenho do animal sem referência; 2. montagem do esquema gráfico; 3 . desenho do animal baseado no esquema gráfico montado.

Nesse artigo será apresentada a trajetória de desenho de animais de uma das participantes, Beta ${ }^{2}$. Era uma menina esperta, gentil e gostava de ajudar os colegas e a professora. Era independente nas tarefas diárias e, segundo as fichas acessadas, também apresentava este mesmo comportamento na escola anterior. Expressava-se bem, apesar dos limites da fala.

Os pais relataram que a partir dos dois anos de idade a menina apresentava atraso na linguagem e no rendimento escolar. Nos anos seguintes, fez tratamento com

2 Nome fictício para preservar a confidencialidade dos dados. 


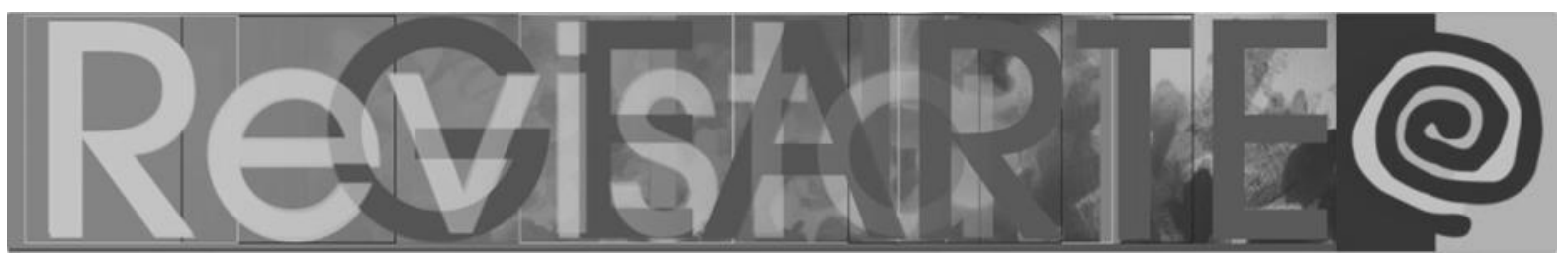

fonoaudiólogo. Sua ficha na instituição informava: atraso no desenvolvimento das funções mentais, da cognição e da linguagem, que são severamente comprometidas. Suas limitações não interferiam nas atividades do cotidiano relacionadas à higiene, alimentação e locomoção. Foi recomendado tratamento fonoaudiólogo e psicopedagógico.

Na mesma ficha, foi pontuado que se o ambiente fosse acolhedor, estimulador e carinhoso seria possível ampliar suas habilidades. Assim, é necessário estabelecer estratégias adequadas às capacidades de aprendizado, evitando que os objetivos educacionais não sejam tão exigentes a ponto de não serem atingidos e nem tão simples que não favoreçam o desenvolvimento.

Percebeu-se que Beta apresentava bom rendimento no decorrer da pesquisa. Escrevia o próprio nome e o nome dos colegas, além de outras palavras, quando soletradas a ela. Precisava de ajuda em tarefas mais complexas, principalmente na realização de novos esquemas gráficos.

O cachorro

O cachorro é um animal de pequeno ou médio porte, com quatro patas, focinho e um rabo. Este último é talvez o elemento de maior expressividade que caracteriza o conceito desse animal. De acordo com Duarte e Piekas (2013) no esquema gráfico de cachorro trabalhado no Vocabulário Pictográfico, o rabo é o elemento de maior expressividade, pois é por meio dele que o cachorro demonstra receptividade, atenção ou medo. No Vocabulário Pictográfico o rabo é desenhado apontado para o alto, ressaltando um caráter amistoso.

Figura 1 - Esquema gráfico de cachorro

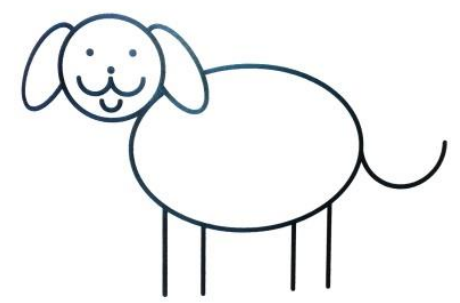

Fonte: Duarte e Piekas (2013). 


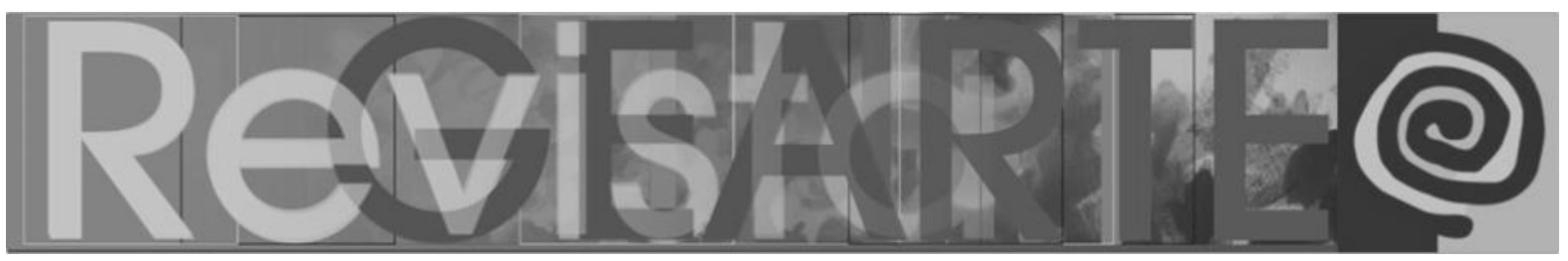

Beta desenhou um esquema de cachorro com uma estrutura parecida com a que iríamos trabalhar (barriga, cabeça, rabo e patas), porém com muitas patas e orelhas (11 patas e 4 orelhas).

Após esses primeiros desenhos, o esquema de cachorro (desenho e jogo) foi mostrado e eu pedi para que comparassem com seus desenhos. Perguntas como: o que há de diferente entre esse desenho e o desenho da Beta? Quantas patas têm esse cachorro? E quantas orelhas? promoveram a reflexão entre os alunos. Para finalizar, foi salientado que o cachorro tem corpo, cabeça, duas orelhas, quatro patas e rabo. O jogo do esquema foi montado pelos participantes sem grandes dificuldades.

Ao desenhar seu segundo cachorro, Beta repetiu o mesmo modelo de corpo, mas acrescentou apenas quatro patas e duas orelhas, deixando de lado a incapacidade sintética visível no primeiro desenho. Além disso, pôde definir melhor os elementos que compõem a cara do animal.

Figura 2 - Desenho de cachorro com referência. Beta, 13 anos

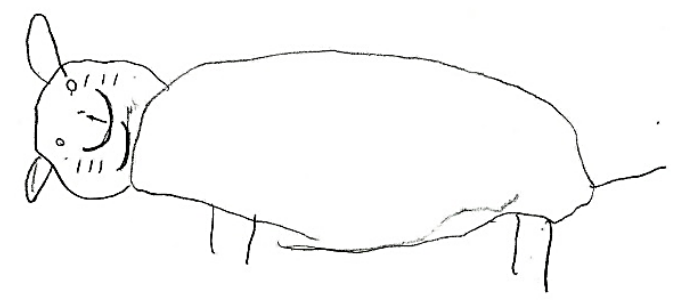

Fonte: Arquivo da autora.

É importante que o professor instigue o aluno com questionamentos a fim de que ele possa refletir e encontrar soluções acerca do problema dado. Mesmo alunos com deficiência são capazes de resolver problemas e criar estratégias para a solução dos problemas, especialmente quando há uma orientação que conduza a esse aprendizado. 


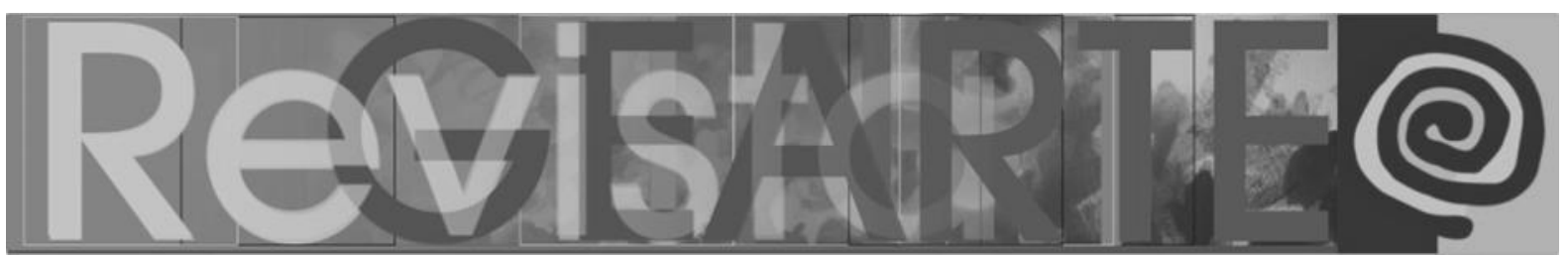

Coelho

O coelho, apesar de não ser um animal tão acessível quanto o cachorro, percorre o imaginário popular em função de ser protagonista de inúmeros desenhos animados e de ser símbolo da Páscoa. Portanto, esquemas de desenhos de coelhos estão por toda parte em detrimento da imagem do coelho real. Em qualquer esquema gráfico desse animal, o elemento mais salientado para caracterizá-lo são as longas orelhas e o rabo "fofinho". Em comparação com o esquema anterior o coelho é um animal de porte pequeno.

Figura 3 - Esquema gráfico de coelho

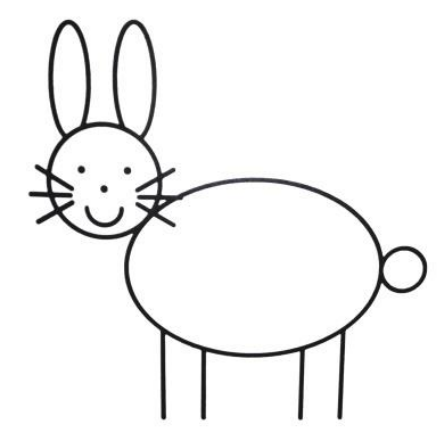

Fonte: Duarte e Piekas (2013).

A proposta para este primeiro encontro destinado ao desenho do coelho se deu da mesma maneira que a proposta anterior. Pedi que imaginassem o animal, suas partes e em seguida o desenhassem. Beta desenhou um coelho parecido como o que já havia feito. Nota-se que ela lembrou do esquema aprendido em encontros anteriores.

Figura 4 - Desenho de coelho sem referências. Beta, 13 anos

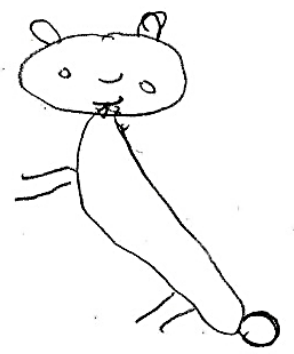

Fonte: Arquivo da autora. 


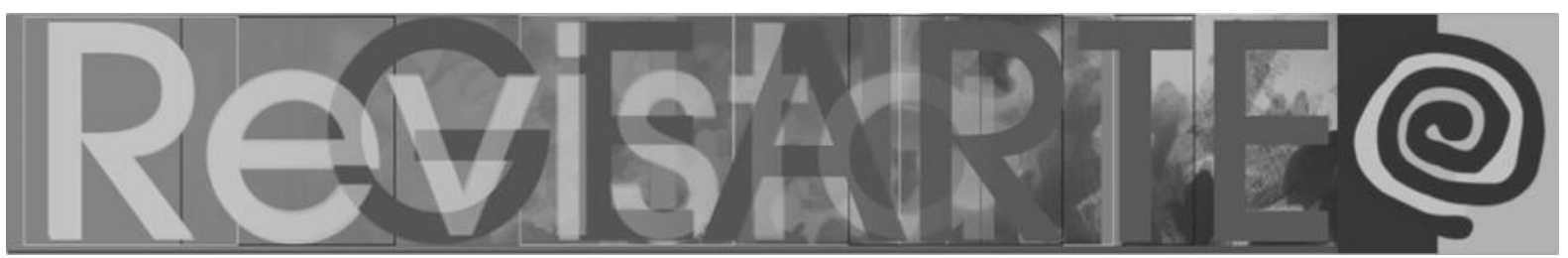

Após a montagem do esquema, os participantes e eu conversamos sobre as diferenças e semelhanças entre os esquemas e seus desenhos. Essa é uma atividade importante visto que a comparação e análise de seus desenhos faz com que os participantes tomem consciência de seus erros e acertos, permitindo verificar o que e como pode ser mudado.

Beta repetiu seu esquema sem apresentar mais detalhes.

Figura 5 - Desenho de coelho com referência. Beta, 13 anos

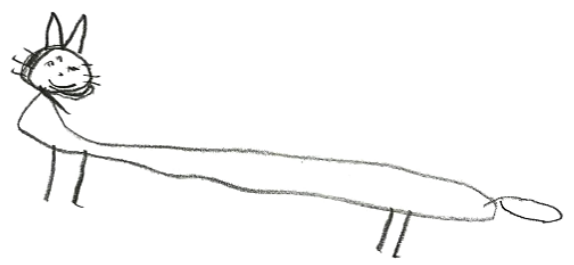

Fonte: Arquivo da autora.

Cavalo

Do ponto de vista formal, o cavalo se distingue dos outros animais trabalhados por ser um animal de grande porte, patas compridas, crina, cabeça e pescoço alongados. Ele possui maior número de elementos com diferentes tipos de linhas, como a crina, que pode ser traduzida por uma linha ondulada ou retas sequenciais ou em zigue-zague, por exemplo. O esquema gráfico de cavalo apresentou um diferencial, proporcionando um novo patamar de dificuldade no momento de realizar a tarefa. A figura do cavalo apresentava um longo pescoço que separa a cabeça do corpo, diferente das figuras restantes, que não possuíam essa característica, pois apresentaram a cabeça junto ao corpo. É muito importante para o aprendizado que o professor lance novos desafios aos educandos após novos conhecimentos já terem sidos internalizados.

Antes de começar a trabalhar com o esquema gráfico, foi pedido, para que os participantes da pesquisa desenhassem um cavalo. Antes de desenharem, foi 


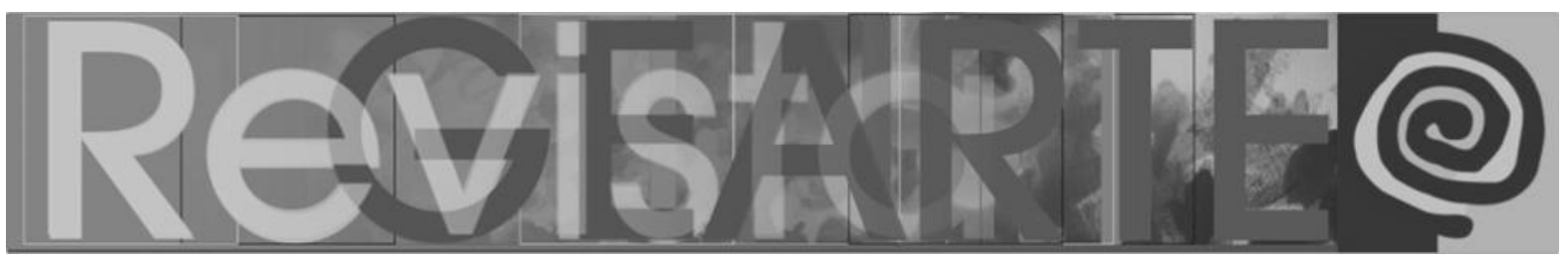

discutido sobre as partes que compõe o animal, como barriga, quatro patas, rabo, crinas, cabeça etc. É importante que o professor processe cada estágio do desenho para criar a habilidade de aprendizado dos diferentes tipos de linhas e formas que compõem a figura.

$\mathrm{Na}$ etapa dois, em que os participantes deveriam montar o esquema do cavalo de acordo com o modelo, pensou-se que enfrentariam maiores dificuldades em relação ao pescoço, porém eles demonstraram que sabiam localizar e posicionar esse elemento com pouca confusão ou ajuda. A crina do animal gerou alguma confusão, quando colocada abaixo do pescoço ou no oval que representa a barriga do animal, como mostram as Figuras 6 e 7.

Após essa etapa, os participantes desenharam o cavalo conforme a referência que haviam acabado de montar.

Figuras 6 e 7 - Primeiro e segundo desenho de Beta após montar o esquema. Beta, 13 anos,
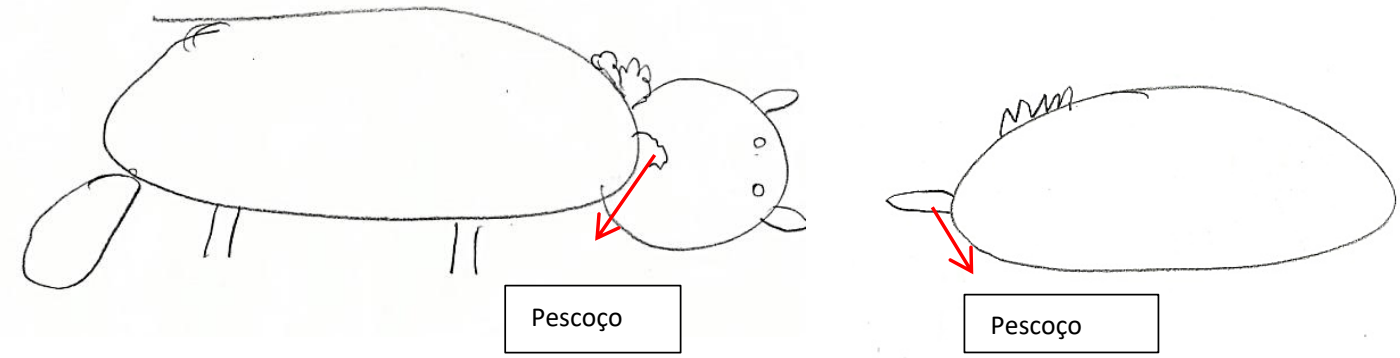

Fonte: Arquivo da autora.

Notou-se que Beta, embora tenha montado o esquema com facilidade, repete o desenho que havia criado antes de montar o esquema, incluindo alguns detalhes como a crina e apenas quatro patas, bem como orelhas menores e mais pontudinhas (Figura 6). Após eu intervir questionando o pescoço e mostrando a disposição desse elemento no jogo de esquema gráfico do cavalo, Beta tenta incluí-lo no desenho. Pedi que ela prestasse mais atenção e repetisse o desenho. Ela repetiu e eu perguntei:

“- Onde está o pescoço o cavalo?

- Aqui! Apontando para o desenho." 


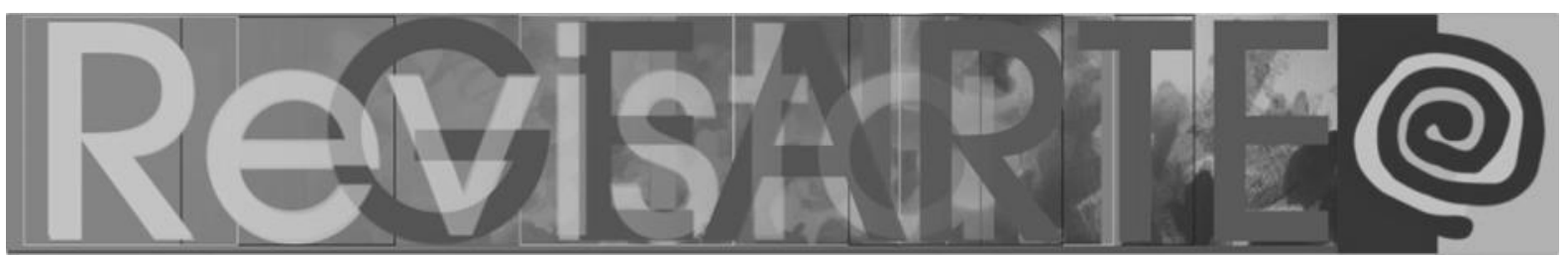

Nesse momento, mostrei em outra folha de papel sulfite como o pescoço do cavalo pode ser construído com duas linhas retas. Em seguida ela desenha um novo cavalo (Figura 8), dando atenção especial para todos os elementos que o caracterizam, embora tenha demonstrado não saber onde encaixar a crina do animal.

Figura 8 - Último desenho de Beta após montar o esquema. Beta, 13 anos

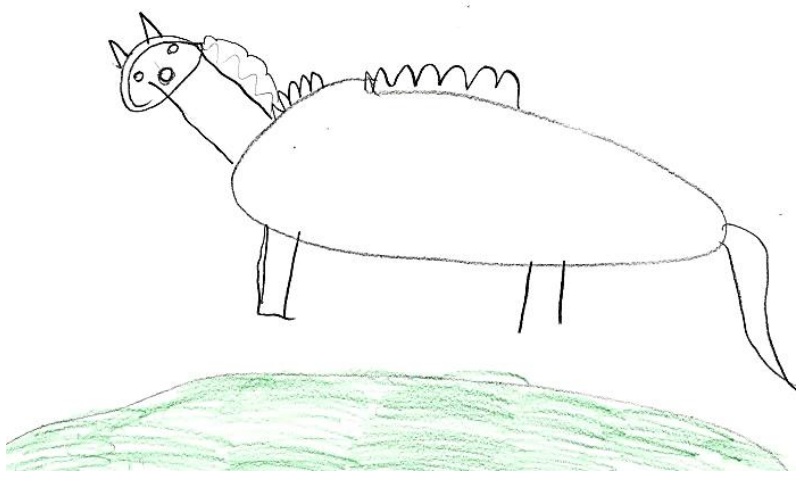

Fonte: Arquivo da autora.

Ainda na mesma imagem Beta desenhou com linhas côncavas as crinas, colocando-a em cima do corpo e, após intervenção da pesquisadora, ela desenha em cima do pescoço.

Gato

O gato é um animal doméstico de pequeno porte, tem quatro patas, pequenas orelhas, rabo comprido e, assim como o coelho, permeia o imaginário das crianças por meio das histórias infantis e desenhos animados como o Gato de Botas e Tom e Jerry. O esquema gráfico do gato ocupou o tempo das duas últimas semanas da coleta de dados.

No primeiro encontro destinado ao desenho do gato, os participantes pareceram estar mais familiarizados com o método de desenhar animais. Apesar de as crianças insistirem muito em desenhar um Papai-Noel, eu salientei que depois de desenhar o gato eles poderiam desenhar um Papai-Noel e inclusive usar lápis de cor para colorir. Nesse encontro seria desenhado o gato sem a referência do jogo do esquema gráfico, que estava previsto para a próxima semana. 


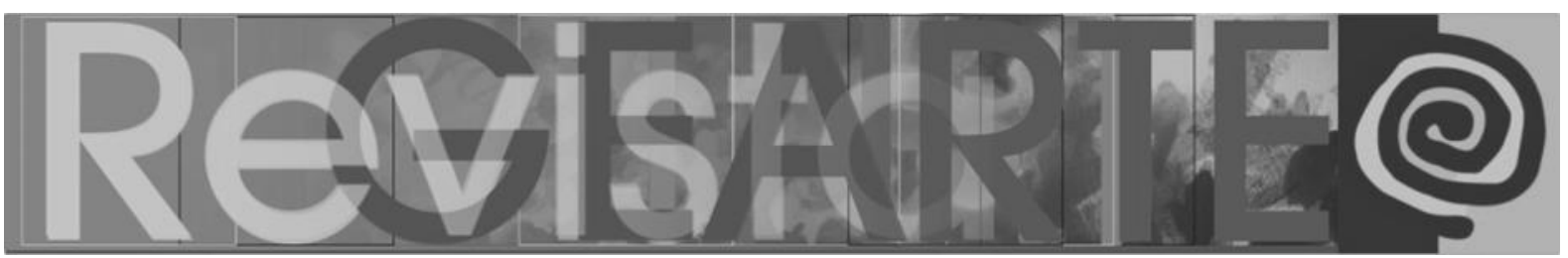

Beta desenhou um esquema de gato completo, mas fez um círculo para o rabo. Questionei sobre o gato ter um rabo igual ao do coelho e ela substituiu por uma linha ondulada. Após desejou desenhar um Papai-Noel:

“- Como se faz um Papai-Noel, professora?

- Da mesma maneira que se faz um homem, mas o Papai-Noel tem barba grande, touca e botas."

Assim fui auxiliando à medida que ela construía o desenho. Beta pediu, também, para que eu soletrasse algumas palavras para que ela pudesse escrevê-las.

Figura 9 - Desenho do esquema gráfico de gato. Beta, 13 anos

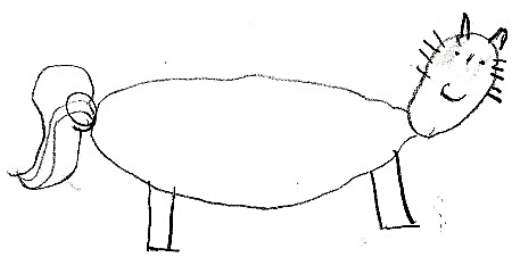

Fonte: Arquivo da autora.

No segundo encontro destinado a esse tema, coloquei na mesa as peças do esquema gráfico de gato e pedi a atenção dos participantes. Beta repetiu o desenho da semana anterior, porém dessa vez acrescentou diversas patas ao animal. Ao final notou que havia esquecido de desenhar o rabo e o faz por último.

Figura 10 - Desenho de Beta após montar o esquema gráfico de gato. Beta, 13 anos

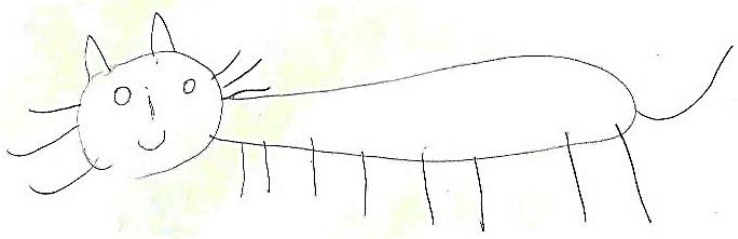

Fonte: Arquivo da autora.

Beta estava sempre disposta a ajudar seus colegas, sem moderação. Quando chegou para a coleta de dados, tinha um repertório bastante limitado de esquemas 


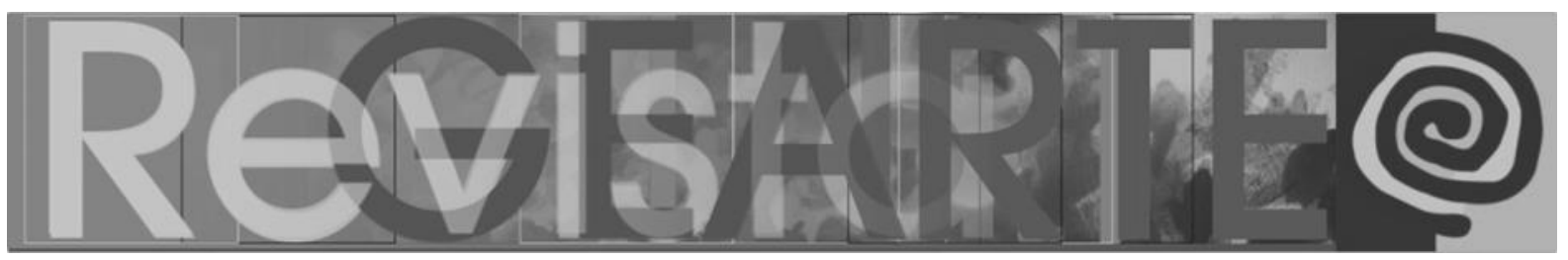

gráficos. Ao final daquele ano já havia internalizado o esquema-base para construção dos animais.

\section{Considerações finais}

De forma resumida, pode-se relatar alguns resultados obtidos ao final desta pesquisa, como o fato de os participantes reconhecerem as partes dos esquemas gráficos, apesar de não conseguirem desenhá-los sem auxílio prévio. Os exercícios que antecederam o desenho dos esquemas foram fundamentais para a compreensão das formas e linhas que compõem os esquemas gráficos. Além disso, os participantes criaram seus próprios recursos de desenhos, contornando os objetos ou solicitando o método de liga-pontos para desenhar a casa, por exemplo. Os participantes da pesquisa também atribuíram significado aos seus desenhos quando complementavam a cena com pormenores que envolviam o ambiente e as características do motivo do esquema gráfico trabalhado.

Da mesma maneira, o esquema-base de construção dos desenhos de animais foi internalizado pelos participantes da turma SAEDE IV, especialmente por Beta, uma vez que desenhava usando a mesma sequência (barriga, cabeça, patas). O esquema de cavalo foi mais audacioso, pois trazia aos participantes uma diferença fundamental em relação aos outros esquemas: o pescoço. Mesmo trabalhando com atividades que demandam maior esforço cognitivo dos participantes, essa dificuldade quando exercitada e repetida pôde ser superada. Barbosa (2014, p. 17), arte-educadora que trabalhou com crianças com paralisia cerebral, ressalta a importância de se alternar atividades simples com atividades mais complexas "[...], pois a capacidade cognitiva da criança filtra aquilo que pode aprender".

Foi possível perceber que o jogo de esquemas gráficos foi o método de ensino mais significativo, pois possibilitou aos participantes a antecipação e melhor compreensão do esquema trabalhado. Isso porque o jogo permitiu compreender as formas geométricas de modo separado do conjunto e relacioná-las, fazendo com que os participantes entendessem que um desenho se faz por etapas. Quando surgiam 


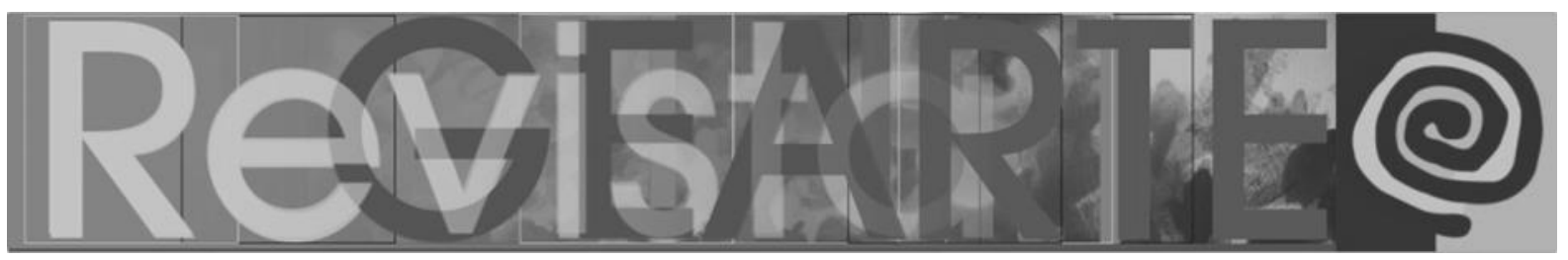

dúvidas na montagem, os participantes podiam montá-lo por cima da referência do esquema gráfico, exposta em outro papel, ou contornar as formas para desenhá-las com maior precisão.

Esse processo de montagem do esquema antes de desenhá-lo mostrou-se significativo no momento em que permitiu às crianças criarem um "modelo interno", ou seja, anteciparem ou formarem uma imagem mental que as permitiu desenhar tal esquema gráfico. Além disso, essa imagem mental ou "modelo interno" contribuiu para a realização de outros desenhos por meio da generalização de suas formas. Foi possível observar isso, especialmente, nos esquemas de animais em que o modelobase dos desenhos (barriga, cabeça, patas) era compartilhado por todos os animais propostos, permitindo a generalização para novos bichos. Beta já havia internalizado o modelo-base de desenho dos animais e, a partir disso, seus animais foram desenhados na horizontal.

Outro ponto importante que pode ser salientado é o fato de que os participantes tiveram a possibilidade de transitar das etapas do Realismo Fortuito e Falhado para um começo do Realismo Intelectual ${ }^{3}$, com desenhos mais organizados no espaço da folha A4 e menos gestos incontrolados ou incapacidade sintética, ou puderam complementar os esquemas trabalhados com outros desenhos na cena. Pode-se concluir que os desenhos passaram pelo que Luquet (1969) chamou de Modificação do Tipo. Além disso, é possível ressaltar a importância de se aprender a desenhar de maneira coletiva e ter modelos bidimensionais como referência. Wilson e Wilson (1997) salientam que crianças aprendem a desenhar observando seus pares fazendo o mesmo. Conforme os autores, as crianças precisam de modelos de desenhos para serem seguidos. "Não será por meio de nenhum tipo de exame das nuvens que a pessoa aprenderá a desenhá-las. [...] Sim, estamos dizendo que, sem modelos para serem seguidos, haveria pequeno ou nenhum comportamento de realização de signos visuais nas crianças." (WILSON; WILSON, 1997, p. 61)

3 Denominações dos estágios do desenho segundo Luquet (1969).

OLEQUES, Liane Carvalho. Desenho infantil e o Ensino de Artes 579 


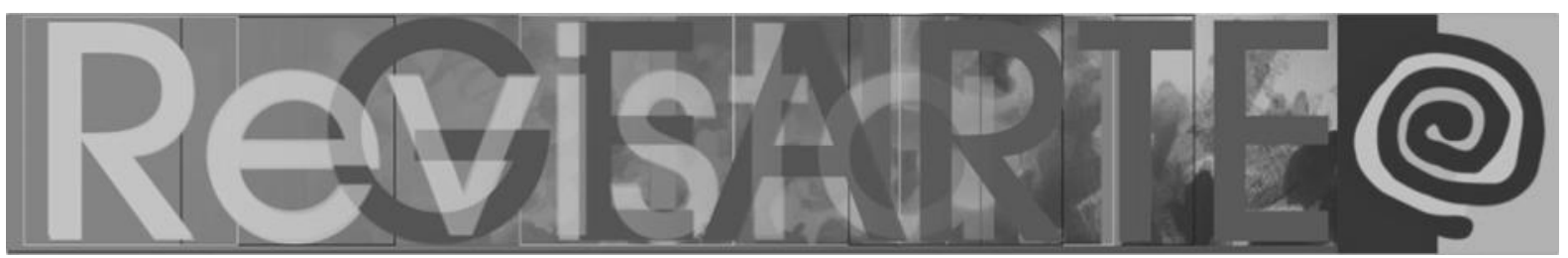

Partindo desse pensamento e fazendo um paralelo com o princípio de Luquet (1969), é possível dizer que as crianças precisam de modelos bidimensionais já resolvidos para criarem seus próprios modelos internos.

As Artes Visuais, como um meio não verbal de comunicação, podem proporcionar para os educandos com deficiência acesso à expressão e imaginação, dando sentido e significado ao seu contexto, além de desenvolver habilidades acerca da motricidade e, como já se enfatizou, de generalizações cognitivas.

Desenhar, pintar, colar ou recortar podem parecer tarefas rotineiras para educandos sem deficiência, em classes comuns de ensino; porém, para alunos com deficiência, essas podem ser grandes barreiras a serem superadas. O professor que trabalha com educandos com deficiência deve, sempre que necessário, ajudá-los e incentivá-los, com paciência, em todas as suas necessidades, esperando pelos resultados, sejam de curto, médio ou longo prazo.

\section{Referências}

BARBOSA, Ana Amália Tavares Bastos. Além do corpo: uma experiência em Arte/Educação. São Paulo: Cortez, 2014.

DUARTE, Maria Lúcia Batezat. Desenho infantil e seu ensino a crianças cegas: razões e método. Curitiba: Insight, 2011.

DUARTE, Maria Lúcia Batezat; PIEKAS, Mari Ines. Vocabulário pictográfico para educação inclusiva. Curitiba: Insight, 2013.

LUQUET, Georges-Henri (1927). O desenho infantil. Porto: Do Minho,1969.

OLEQUES, Liane Carvalho. Imagem e palavra: um estudo do desenho infantil em um caso de surdez profunda. 2010. Dissertação (Mestrado em Artes Visuais) - Programa de Pós-Graduação em Artes Visuais, Universidade do Estado de Santa Catarina. Florianópolis, 2010.

OLEQUES, Liane Carvalho. Uma possibilidade de ensino de desenho para crianças com deficiência intelectual. 2017. Tese (Doutorado em Artes Visuais) - Programa de Pós-Graduação em Artes Visuais, Universidade do Estado de Santa Catarina. Florianópolis, 2017.

WILSON, Brent; Wilson, Marjorie. Uma visão iconoclasta das fontes de imagens nos desenhos de crianças. In: BARBOSA, Ana Mae. (Org.). Arte-educação: leitura no subsolo. São Paulo: Cortez, 1997.

\section{Liane Carvalho Oleques}

Doutora em Artes Visuais pela Universidade do Estado de Santa Catarina (UDESC), bolsista CAPES/FAPESC. Mestre em Artes Visuais pela mesma Universidade, ambos na Linha de Pesquisa Ensino das Artes Visuais. Possui Graduação e Licenciatura Plena em Desenho e Plástica pela

OLEQUES, Liane Carvalho. Desenho infantil e o Ensino de Artes 580

Visuais: desenhando com crianças com deficiência intelectual.

Revista GEARTE, Porto Alegre, v. 6, n. 3, p. 564-581, set./dez. 2019.

Disponível em: http://seer.ufrgs.br/gearte 


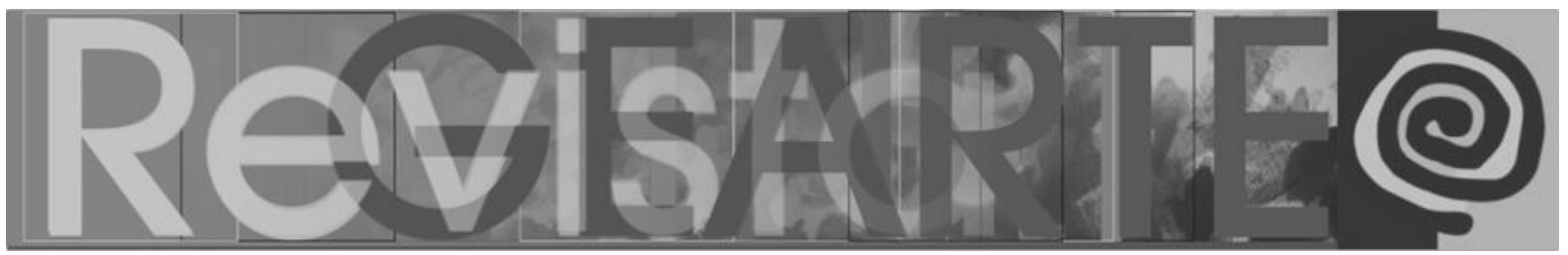

Universidade Federal de Santa Maria (UFSM). Foi membro do Grupo de Pesquisa Imagem, Arte e Desenho na Escola, GIADE, e do Laboratório de Pesquisa em Desenho Infantil e Adolescente, LabDIA. Atuou como professora na Educação Infantil, Fundamental, Ensino Superior e Educação Especial. Atualmente trabalha como professora de Artes Visuais na APAE/PALHOÇA.

E-mail: lioleques@gmail.com

Currículo: http://lattes.cnpq.br/0890473214453132

Recebido em 28 de abril de 2019 Aceito em 1 de setembro de 2019 